Proses produksi bioetanol dari limbah cair gula... (Agusta Samodra Putra, dkk)

\title{
PROSES PRODUKSI BIOETANOL DARI LIMBAH CAIR GULA DALAM KAITANNYA DENGAN POTENSI SEBAGAI BAHAN BAKAR DALAM PERSPEKTIF LIFE CYCLE INVENTORY ASSESSMENT
}

\author{
*Agusta Samodra Putra', Hari Rom Hariyadi ${ }^{1}$, Herlian Eriska Putra ${ }^{1}$, Djaenudin", Dani \\ Permana $^{1}$, dan Kancitra Pharmawati ${ }^{2}$ \\ ${ }^{1}$ Pusat Penelitian Kimia LIPI,Kawasan Puspiptek, Serpong \\ ${ }^{1}$ Pusat Penelitian Kimia, Komplek LIPI, Jl. Cisitu Sangkuriang, Bandung \\ ${ }^{2}$ Program Studi Teknik Lingkungan, Institut Teknologi Nasional, Jl. PHH Mustafa No. 23, \\ Bandung \\ *email: chemguzta@gmail.com
}

\begin{abstract}
ABSTRAK
Life cycle inventory assessment merupakan salah satu tahapan di dalam Life Cycle Assessment (LCA) yang bisa digunakan untuk menggambarkan interaksi materi dan energi di dalam suatu proses produksi bioetanol. Studi kasus dilakukan di pabrik gula kawasan Subang dan pabrik bioetanol di kawasan Palimanan yang merupakan pabrik gula dan bioetanol terbesar di Jawa Barat. Inventory yang dilakukan adalah pada bagian perkebunan tebu, pabrikasi tebu menjadi gula, transportasi dari pabrik gula menuju ke pabrik bioetanol, dan pabrikasi etanol. Luas lahan kebun tebu yang dimiliki oleh pabrik gula di Subang adalah seluas 5000 hektar. Dari bahan baku tebu 3000 ton/hari dihasilkan molase sebanyak 60 ton/hari, sisanya menjadi gula dan ampas tebu. Pada inventory kali ini selain dari sisi proses juga dilakukan inventory pada sisi transportasi.
\end{abstract}

Kata kunci : Life Cycle Inventory Assessment, bioetanol, molase

\section{BIOETHANOL PRODUCTION PROCESS FROM SUGAR WASTEWATER (MOLASE) AS A POTENTIAL FUEL IN LIFE CYCLE INVENTORY PERSPECTIVE}

\begin{abstract}
Life cycle inventory assessment is one of the steps in a Life Cycle Assessment (LCA) which could be used for describing the interaction of matter and energy in a process for the production of bioethanol. A case study that conducted in the sugar mills in Subang region and bioethanol plant in Palimanan region which is the largest sugar mill and ethanol in West Java Province. Inventory conducted to sugarcane plantation, a sugar manufacturing, transportation from the factory of sugar to ethanol plant and process of ethanol manufacturing. The area that are covered by sugarcane plantation owned by a sugar factory in Subang is approximately 5000 hectares. From raw material of sugarcane is 3000 tons / day and molasses that are produced is 60 tons / day, and the rest are being sugar and bagasse. Additional information for this inventory was done on the transportation side.
\end{abstract}

Keyword : Life Cycle Inventory Assessment, bioethanol, molases 


\section{PENDAHULUAN}

Beberapa jenis tanaman budidaya seperti jagung, gandum, gula bit, singkong, sorgum manis, dan tebu telah umum dimanfaatkan dalam produksi bioetanol. Pemanfaatan tanaman ini secara langsung untuk pembuatan bioetanol dikategorikan sebagai bioetanol generasi pertama. Pembuatan bioetanol generasi kedua memanfaatkan biomassa berupa residu non pangan seperti sampah kebun, limbah kayu, tongkol jagung, jerami dan tandan kosong kelapa sawit. Pada Life Cycle Inventory (LCI) kali ini akan difokuskan pada proses produksi bioetanol yang berasal dari limbah tebu (molase) yang dapat dikategorikan bioetanol generasi kedua karena memanfaatkan limbah dan bukan berasal langsung dari tanaman.

Meningkatnya produksi gula tebu di Indonesia sekitar sepuluh tahun terakhir ini, tentunya akan meningkatkan produksi molase. Molase merupakan media fermentasi yang baik, karena mengandung gula, sejumlah amino dan mineral, setelah itu molase tersebut diolah menjadi berbagai macam produk seperti gula cair dari tetes, penyedap makanan (MSG) dan pakan ternak. Molase tidak layak untuk dikonsumsi secara langsung karena di dalam molase terdapat banyak kotorankotoran non gula yang dapat membahayakan kesehatan.
LCI merupakan salah satu tahapan di dalam Life cycle assessment (LCA) yang merupakan suatu metode pengukuran dampak suatu produk tertentu terhadap ekosistem yang dilakukan dengan cara mengidentifikasi, mengukur, menganalisis dan menakar besarnya konsumsi energi dan bahan baku, emisi serta faktor-faktor lainnya yang berkaitan dengan produk sepanjang siklus hidupnya (Svoboda, 1995). LCA merupakan evaluasi dari dampak teknologi, ekonomi dan lingkungan yang relevan dari proses, produk atau sektor perekonomian sepanjang siklus hidup (Curran, 1996; Schempf,1999). Proses LCI yang dilakukan kali ini dilakukan pada bagian perkebunan tebu, pabrikasi tebu menjadi gula, transportasi dari pabrik gula menuju ke pabrik bioetanol, dan pabrikasi etanol (from cradle to gate).

Perkembangan metodologi LCA dimulai pada tahun 1970an oleh US Environmental Protection Agency (EPA) yang dikenal dengan pendekatan Resource and Environmental Profile Analysis (REPA). Kebanyakan dari pendekatan REPA berkaitan dengan krisis minyak yang terjadi pada tahun 1973 (Hunt et al, 1992). Pada akhir 1970 an hingga awal 1980 an para pecinta lingkungan fokus pada penanganan bahan berbahaya dan beracun sehingga konsep

Tabel 1. Data Peningkatan Produksi Molase Secara Nasional (BPS, 2006)

\begin{tabular}{|c|c|c|}
\hline Tahun & Kuantitas $(\mathbf{K g})$ & Persentase \\
\hline 1997 & 1.267 .990 .000 & 14,06 \\
\hline 1998 & 1.415 .115 .971 & 15,07 \\
\hline 2000 & 1.536 .200 .007 & 17,04 \\
\hline 2001 & 1.829 .745 .972 & 20,30 \\
\hline 2002 & 2.966 .023 .440 & 32,90 \\
\hline
\end{tabular}


LCA dikaitkan dengan metode mengenai analisis resiko (Stilwell et al, 1991). Ketika limbah padat menjadi fokus pada akhir 1980an LCA dilengkapi dengan analisa mengenai masalah limbah padat untuk keperluan Council for Solid Waste Solutions (CSWS, 1990).

Pemanfaatan bioetanol sebagai bahan bakar bukan merupakan hal baru dan telah diterapkan di banyak negara. Keberlanjutan bahan bakar bioetanol generasi pertama ini masih diperdebatkan karena membutuhkan sumber daya lahan, air dan energi. Manfaat penggunaan bioetanol sebagai bahan bakar, antara lain mengurangi ketergantungan terhadap bahan bakar fosil, mengurangi efek rumah kaca, dan sebagai diversifikasi energi.

Bioetanol di Indonesia diperoleh dari ubi kayu, ubi jalar, sagu, tebu dan jagung. Pemanfaatan bioetanol sebagai bahan bakar alternatif pengganti BBM ini mengacu Keputusan Dirjen Migas No. 23204.K/10/DJM.S/2008, tentang Standar dan Mutu (Spesifikasi) Bahan Bakar Nabati (Biofuel) jenis Bioetanol sebagai Bahan Bakar lain yang dipasarkan di Dalam Negeri, serta mengacu SNI 7390:2008. Spesifikasi dan standar mutu BBM diatur dalam Keputusan Dirjen Migas No. 3674K/24/DJM/2006 (Kussuyani, 2009).

Keunggulan menerapkan LCI yang merupakan bagian dari LCA, yaitu membantu untuk lebih mengerti dampak lingkungan dari keseluruhan operasinya, barang dan jasa, dan kemudian digunakan untuk mengidentifikasi peluang bagi perbaikan sehingga dapat mengkuantifikasi potensi. Beberapa manfaat dan keunggulan LCA, antara lain :

- Pengambilan keputusan yang lebih baik tentang pemilihan produk dan sistem produksi.

- Sistematis memperkirakan konsekuensi lingkungan dan menganalisis pertukaran yang terjadi terhadap lingkungan dan terkait dengan produk yang diperiksa atau diproses.

- Untuk mengidentifikasikan dampak utama terhadap lingkungan dan tahap-tahap daur hidup produk.

- Perbaikan produk : LCA dapat mengidentifikasi pilihan biaya paling efisien dan efektif bagi pengurangan dampak lingkungan dari produk atau jasa. Perbaikan semacam itu dapat membuat produk lebih diinginkan oleh konsumen. Menyediakan langkahlangkah perbaikan yang berbasis lingkungan.

- Perbaikan proses. LCA dapat digunakan untuk menangani operasi dan proses produksi perusahaan. Ini adalah cara yang berguna untuk menghitung sumberdaya dan penggunaan energi. Ini dapat menawarkan pilihan bagi perbaikan efisiensi seperti menghindari pengolahan limbah, penggunaan sumberdaya lebih sedikit, dan memperbaiki kualitas perakitan.

- Memberikan solusi atas informasi yang keliru.

- Perencanaan strategis. LCA dapat digunakan sebagai perencanaan strategis. Begitu peraturan lingkungan dan harapan lingkungan meningkat, terdapat kecenderungan peningkatan tekanan bagi perusahaan untuk memperbaiki operasi lingkungan mereka. Kinerja lingkungan juga cenderung menjadi lebih kritis bagi daya kompetisi internasional.

Adapun kelemahan LCA antara lain :

- Studi LCA cukup mahal secara ekonomi, karena prosedur LCA yang sangat intensif dan memakan waktu. 


\section{METODOLOGI}

Metodologi LCA menurut Inteernational Standart of Organization (ISO)-14040, dibagi menjadi 4 tahapan : tujuan dan cakupan (ISO 14040), analisis inventori (ISO 14041), penakaran dampak (ISO 14042), interpretasi dan analisa perbaikan (ISO 14043). Dalam LCI kali ini menggunakan ISO 14041. Basis perhitungan untuk normalisasi satuannya menggunakan kapasitas produksi masingmasing ruang lingkup.

\section{HASIL DAN PEMBAHASAN}

LCI terbagi menjadi tiga tahap yaitu mulai dari perkebunan tebu, pabrikasi gula, dan pabrikasi bioetanol. Seluruh bagian LCI meliputi bagian proses beserta transportasinya.

Luas lahan perkebunan tebu yang dimiliki oleh pabrik gula Subang adalah seluas 5000 ha. Tebu dipanen setiap 12 bulan sekali dan dalam setiap hari tebu yang dibutuhkan untuk proses produksi gula sebanyak 3000 ton / hari.

Proses pengangkutan tebu dari perkebunan tebu ke pabrik gula menggunakan truk dengan jarak $3 \mathrm{~km}$. Bahan bakar yang digunakan truk yaitu solar dengan kapasitas tangki 80 liter. Kapasitas truk pengangkut tebu adalah 200 ton sehingga dalam sehari solar yang dibutuhkan adalah 30 liter.

Tebu sebagai bahan baku utama di proses sampai menghasilkan produk akhir berupa kristal gula. Selain menghasilkan produk gula, tebu menghasilkan produk sampingan berupa tetes (molase). Molase dimanfaatkan sebagai bahan baku pembuatan bioetanol.

Tabel 2 Perhitungan Beban Pencemar Transportasi dari Perkebunan Tebu ke Pabrik Gula (Studi Kasus Pabrik Gula Subang)

\begin{tabular}{|l|c|c|c|c|}
\hline \multirow{2}{*}{ Jenis Kendaraan } & \multicolumn{4}{|c|}{ Liter/hari } \\
\cline { 2 - 5 } & $\mathbf{C O}$ & $\mathbf{C O}_{2}$ & $\mathbf{N O}$ & $\mathbf{S O}_{\mathbf{2}}$ \\
\hline \multirow{2}{*}{ Truk } & $6,05 \times 10^{-4}$ & 0,14 & $7,2 \times 10^{-}$ & $8,9 \times 10^{-7}$ \\
\hline
\end{tabular}

(Sumber: Perhitungan, Modifikasi dari Samhan, 2012)

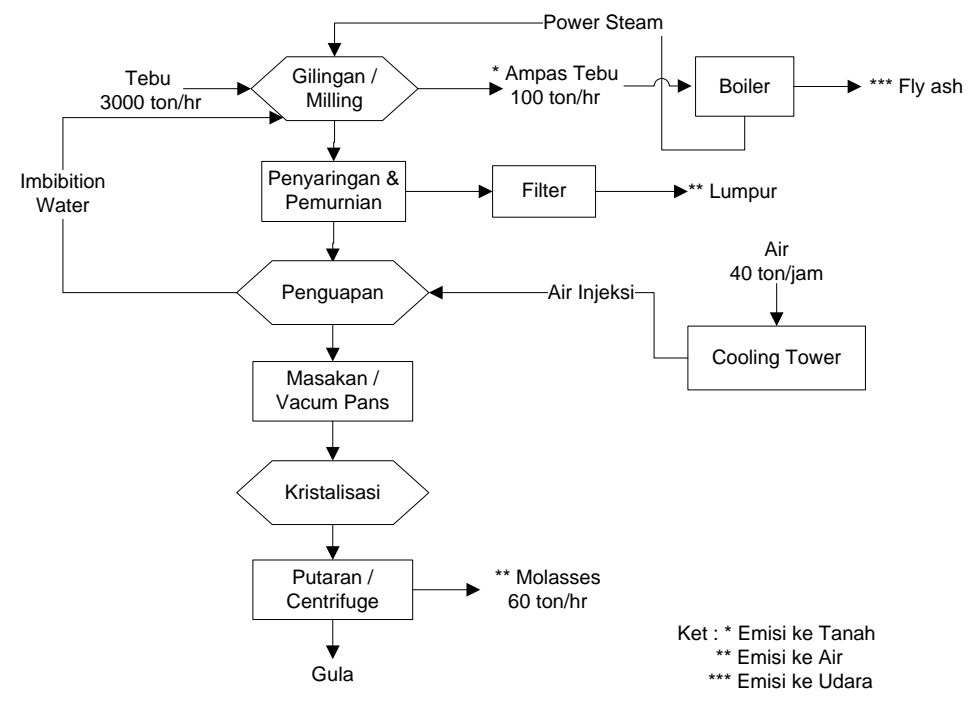

Gambar 1 Proses Industri Gula (Pabrik Gula di Subang, Jawa Barat) 
Tabel 3 Perhitungan Beban Pencemar Transportasi Molase dari Industri Gula menuju Pabrik Bioetanol

\begin{tabular}{|c|c|c|c|c|c|c|c|}
\hline \multirow{2}{*}{$\begin{array}{c}\text { Jenis } \\
\text { Kendaraan }\end{array}$} & \multicolumn{7}{|c|}{ ton/tahun } \\
\cline { 2 - 8 } & $\mathbf{C O}$ & $\mathbf{C O}_{\mathbf{2}}$ & $\mathbf{H C}$ & $\mathbf{P M}_{\mathbf{1 0}}$ & $\mathbf{P M}_{\mathbf{2}, \mathbf{5}}$ & $\mathbf{N O}_{\mathbf{X}}$ & $\mathbf{S O}_{\mathbf{2}}$ \\
\hline Truk & 0,37 & 138,94 & 0,079 & 0,061 & $\begin{array}{c}1,97 \times 10^{-} \\
3\end{array}$ & 0,78 & 0,036 \\
\hline
\end{tabular}

(Sumber Perhitungan, Modifikasi dari Samhan, 2012)

Bahan baku utama untuk membuat gula yaitu tebu, dimana tebu menghasilkan limbah yang dapat dimanfaatkan yaitu molase. Molase dapat dimanfaatkan menjadi bioetanol. Molase yang dihasilkan dari proses produksi gula di PG. X, Subang sebanyak 60 ton/hari atau $41.379 \mathrm{~L} / \mathrm{hari}$. Selain molase limbah yang dapat dimanfaatkan dari sisa proses produksi gula yaitu ampas tebu. Ampas tebu di PG. $\mathrm{X}$, Subang dimanfaatkan sebagai bahan bakar untuk boiler. Dalam sehari ampas tebu yang diperlukan untuk kebutuhan boiler sebanyak $800.000 \mathrm{~L} /$ hari.

Pada proses di pabrik bioetanol, molase diencerkan terlebih dahulu dengan air sebanyak $12.000 \mathrm{~kg} /$ hari, karena kadar gula dalam molase masih terlalu tinggi untuk menuju proses fermentasi. Setelah molase encer, lalu dimasukan kedalam dandang pencampur dengan ditambahkan $\mathrm{H}_{2} \mathrm{SO}_{4}$ sebanyak 3.000 liter yang bertujuan agar $\mathrm{pH}$ mendekati netral. Sebelum memasuki proses fermentasi, dilakukan pembibitan dengan menggunakan ragi yaitu saccharomyces cerevicesiae sebanyak $1.500 \mathrm{~kg} / \mathrm{hr}$ yang berfungsi untuk merubah gula menjadi etanol dan ditambahkan urea sebagai nutrisi bagi saccharomyces cerevicesiae, banyaknya urea yang ditambahkan yaitu $1 \%$ dari molase yang akan difermentasi yaitu 600 $\mathrm{kg} / \mathrm{hari}$. Lalu cairan dari dandang pencampur dialirkan kedalam pembibitan dan dilakukan proses fermentasi. Proses fermentasi diakhiri dengan adanya gelembung-gelembung udara, setelah itu dilakukan proses distilasi yang berfungsi agar etanol yang dinginkan sesuai standar perusahaan yaitu 98\% dan pada proses distilasi terjadi penguapan yang menghasilkan uap air sebanyak 17.020 $\mathrm{kg} / \mathrm{hari}$. Dari hasil inventarisasi maka dibuatlah sebuah result profile from cradle to gate dari perkebunan tebu hingga industri bioetanol.

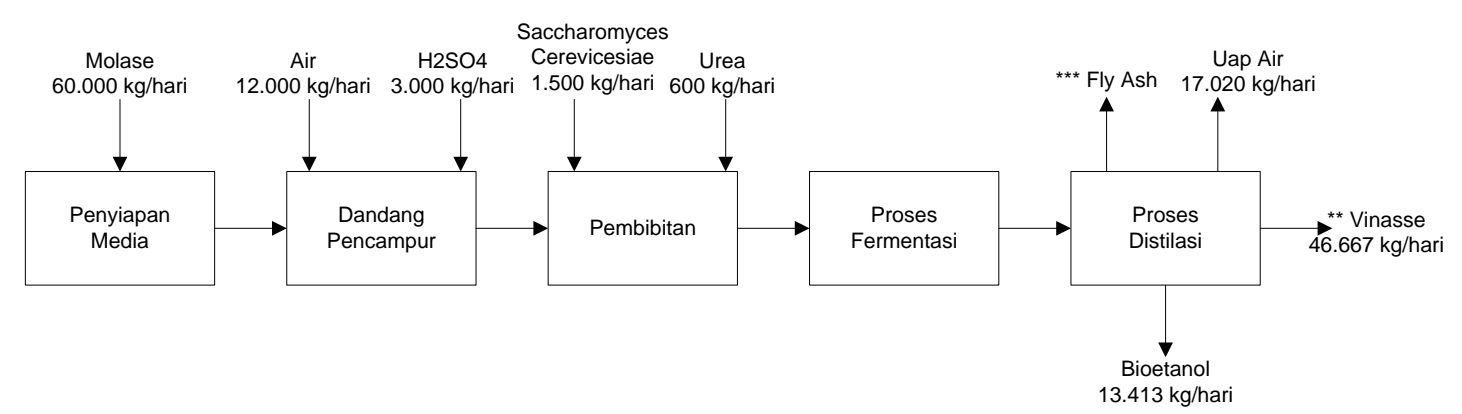

Gambar 2 Proses Produksi Bioetanol (Sumber : Pabrik Bioetanol di Palimanan) 
Tabel 4 Result Profile Life Cycle Inventory (LCI) untuk Proses Produksi Bioetanol Berbahan Baku Molase

\begin{tabular}{|c|c|c|c|}
\hline $\begin{array}{c}\text { 1.Transportasi dari } \\
\text { Perkebunan ke Pabrik Gula }\end{array}$ & Data & Satuan & $\begin{array}{l}\text { Equivalent Value } \\
\text { (indeks) }\end{array}$ \\
\hline \multicolumn{4}{|l|}{ Inflow } \\
\hline Solar & 409 & Liter & \\
\hline \multicolumn{4}{|l|}{ Outflow } \\
\hline $\mathrm{CO}$ & 5,52 & ton/tahun & \\
\hline $\mathrm{CO}_{2}$ & 2.084 & ton/tahun & \\
\hline $\mathrm{HC}$ & 1,18 & ton/tahun & \\
\hline $\mathrm{PM}_{10}$ & 0,92 & ton/tahun & \\
\hline $\mathrm{PM}_{2,5}$ & 0,029 & ton/tahun & \\
\hline $\mathrm{NO}_{\mathrm{x}}$ & 11,63 & ton/tahun & \\
\hline $\mathrm{SO}_{2}$ & 0,54 & ton/tahun & \\
\hline 2. Pabrikasi Gula & Data & Satuan & $\begin{array}{l}\text { Equivalent Value } \\
\text { (indeks) }\end{array}$ \\
\hline \multicolumn{4}{|l|}{ Inflow } \\
\hline Tebu & 3.000 .000 & $\mathrm{~kg} / \mathrm{hari}$ & 50 \\
\hline Air & 960.000 & $\mathrm{~kg} / \mathrm{hari}$ & 16 \\
\hline $\mathrm{Ca}(\mathrm{OH})_{2}$ & $4,45 \times 10^{-4}$ & $\mathrm{~kg} / \mathrm{hari}$ & $7,42 \times 10^{-9}$ \\
\hline $\mathrm{SO}_{2}$ & $2 \times 10^{-6}$ & $\mathrm{~kg} / \mathrm{hari}$ & $3,33 \times 10^{-11}$ \\
\hline \multicolumn{4}{|l|}{ Outflow } \\
\hline Gula & 200.000 & $\mathrm{~kg} / \mathrm{hari}$ & 3,33 \\
\hline Molase & 60.000 & $\mathrm{~kg} / \mathrm{hari}$ & 1 \\
\hline Sludge & 1.275 .000 & $\mathrm{~kg} / \mathrm{hari}$ & 21,25 \\
\hline Uap air & 325.000 & $\mathrm{~kg} / \mathrm{hari}$ & 5,4 \\
\hline Air imbibisi & 570.000 & $\mathrm{~kg} / \mathrm{hari}$ & 9,5 \\
\hline Ampas tebu & 1.530 .000 & $\mathrm{~kg} / \mathrm{hari}$ & 25,5 \\
\hline 3. Energi di Pabrikasi Gula & Data & Satuan & $\begin{array}{c}\text { Equivalent Value } \\
\text { (indeks) }\end{array}$ \\
\hline \multicolumn{4}{|l|}{ Inflow } \\
\hline Ampas tebu & 1.530 .000 & $\mathrm{~kg} / \mathrm{hari}$ & 25,5 \\
\hline \multicolumn{4}{|l|}{ Outflow } \\
\hline Heat & 1.530 .000 & $\mathrm{~kg} / \mathrm{hari}$ & 25,5 \\
\hline $\mathrm{NH}_{3}$ & $5,04 \times 10^{-8}$ & $\mathrm{~kg} / \mathrm{hari}$ & $8,4 \times 10^{-13}$ \\
\hline $\mathrm{NO}_{2}$ & $2,88 \times 10^{-8}$ & $\mathrm{~kg} / \mathrm{hari}$ & $4,8 \times 10^{-13}$ \\
\hline $\mathrm{SO}_{2}$ & $2,77 \times 10^{-6}$ & $\mathrm{~kg} / \mathrm{hari}$ & $4,6 \times 10^{-11}$ \\
\hline $\mathrm{H}_{2} \mathrm{~S}$ & $5,97 \times 10^{-8}$ & $\mathrm{~kg} / \mathrm{hari}$ & $1 \times 10^{-12}$ \\
\hline $\mathrm{CO}$ & 0,0216 & $\mathrm{~kg} / \mathrm{hari}$ & $3,6 \times 10^{-7}$ \\
\hline TSP & $7,56 \times 10^{-4}$ & $\mathrm{~kg} / \mathrm{hari}$ & $1,3 \times 10^{-8}$ \\
\hline $\begin{array}{l}\text { 4. Transportasi Molase dari } \\
\text { Pabrik Gula ke Pabrik } \\
\text { Bioetanol }\end{array}$ & Data & Satuan & $\begin{array}{c}\text { Equivalent Value } \\
\text { (indeks) }\end{array}$ \\
\hline \multicolumn{4}{|l|}{ Inflow } \\
\hline Solar & 409 & liter & \\
\hline \multicolumn{4}{|l|}{ Outflow } \\
\hline $\mathrm{CO}$ & 5,52 & ton/tahun & \\
\hline
\end{tabular}




\begin{tabular}{|c|c|c|c|}
\hline $\mathrm{CO}_{2}$ & 2.084 & ton/tahun & \\
\hline $\mathrm{HC}$ & 1,18 & ton/tahun & \\
\hline $\mathrm{PM}_{10}$ & 0,92 & ton/tahun & \\
\hline $\mathrm{PM}_{2,5}$ & 0,029 & ton/tahun & \\
\hline $\mathrm{NO}_{\mathrm{x}}$ & 11,63 & ton/tahun & \\
\hline $\mathrm{SO}_{2}$ & 0,54 & ton/tahun & \\
\hline 5. Pabrikasi Bioetanol & Data & Satuan & $\begin{array}{c}\text { Equivalent Value } \\
\text { (indeks) }\end{array}$ \\
\hline \multicolumn{4}{|l|}{ Inflow } \\
\hline Molase & 60.000 & $\mathrm{~kg} / \mathrm{hari}$ & 4 \\
\hline Air & 12.000 & $\mathrm{~kg} / \mathrm{hari}$ & 0,9 \\
\hline $\mathrm{H}_{2} \mathrm{SO}_{4}$ & 3.000 & $\mathrm{~kg} / \mathrm{hari}$ & 0,22 \\
\hline Saccharomycess cervicesiae & 1.500 & $\mathrm{~kg} / \mathrm{hari}$ & 0,11 \\
\hline Urea & 600 & $\mathrm{~kg} / \mathrm{hari}$ & 0,045 \\
\hline \multicolumn{4}{|l|}{ Outflow } \\
\hline Bioethanol & 13.413 & $\mathrm{~kg} / \mathrm{hari}$ & 1 \\
\hline Vinasse & 46.667 & $\mathrm{~kg} / \mathrm{hari}$ & 3,48 \\
\hline Uap air & 17.020 & $\mathrm{~kg} / \mathrm{hari}$ & 1,27 \\
\hline $\begin{array}{c}\text { 6. Energi di Pabrikasi } \\
\text { Bioetanol }\end{array}$ & Data & Satuan & $\begin{array}{c}\text { Equivalent Value } \\
\text { (indeks) }\end{array}$ \\
\hline \multicolumn{4}{|l|}{ Inflow } \\
\hline Gas & 5,4 & $\mathrm{~kg} / \mathrm{hari}$ & 0,000403 \\
\hline Solar & 64 & $\mathrm{~kg} / \mathrm{hari}$ & 0,005 \\
\hline Kayu & 30.000 & $\mathrm{~kg} / \mathrm{hari}$ & 2,23 \\
\hline \multicolumn{4}{|l|}{ Outflow } \\
\hline Heat & $30.069,4$ & $\mathrm{~kg} / \mathrm{hari}$ & 2,24 \\
\hline $\mathrm{NH}_{3}$ & $1,37 \times 10^{-6}$ & $\mathrm{~kg} / \mathrm{hari}$ & $4,34 \times 10^{-10}$ \\
\hline $\mathrm{NO}_{2}$ & $1,41 \times 10^{-5}$ & $\mathrm{~kg} / \mathrm{hari}$ & $4,47 \times 10^{-9}$ \\
\hline $\mathrm{SO}_{2}$ & $2,95 \times 10^{-4}$ & $\mathrm{~kg} / \mathrm{hari}$ & $9,35 \times 10^{-8}$ \\
\hline $\mathrm{H}_{2} \mathrm{~S}$ & $3,024 \times 10^{-8}$ & $\mathrm{~kg} / \mathrm{hari}$ & $9,58 \times 10^{-12}$ \\
\hline $\mathrm{CO}$ & $1,73 \times 10^{-9}$ & $\mathrm{~kg} / \mathrm{hari}$ & $5,48 \times 10^{-13}$ \\
\hline TSP & 0,48 & $\mathrm{~kg} / \mathrm{hari}$ & $1,52 \times 10^{-4}$ \\
\hline $\mathrm{Pb}$ & $1,58 \times 10^{-10}$ & $\mathrm{~kg} / \mathrm{hari}$ & $5,01 \times 10^{-14}$ \\
\hline $\mathrm{O} 3$ & $3 \times 10^{-13}$ & $\mathrm{~kg} / \mathrm{hari}$ & $9,51 \times 10^{-17}$ \\
\hline
\end{tabular}

(Sumber: Perhitungan dan Hasil Pengukuran oleh Pabrik Gula di Subang dan Pabrik Bioetanol di Palimanan, 2012)

\section{KESIMPULAN}

Dari hasil LCI didapatkan berbagai komponen yang berdampak pada lingkungan dan keseluruhan komponen bahan yang terlibat di dalam daur hidup dari produk bioetanol. Perlu adanya studi kasus dalam ruang lingkup yang lebih luas agar hasil result profile bisa lebih mewakili.

\section{UCAPAN TERIMA KASIH}

Ucapan terima kasih kami sampaikan kepada Fitria Isti Haula (ITENAS) dan Mahyar Ependi (BTL P2K LIPI Bandung), Pabrik Bioetanol di Palimanan, Pabrik Gula di Subang. 


\section{DAFTAR PUSTAKA}

Anonnymous, 2008. Potensi Pemanfaatan Bioetanol di Indonesia, http://www.pertamina.com/index.p $\mathrm{hp} /$ detail/read/pertamax September 2011)

BPS. Data Impor Indonesia. Badan Pusat Statistik. (2006)

Council for Solid Waste Solutions. "Resource and Environmental Profile Analysis of Polyethylene and Unbleached Paper Grocery Sacks." CSWS (800-243-5790), Washington DC, June 1990

Curran, Mary Ann. Environmental LifeCycle Assessment. McGraw-Hill, New York. (1996)

Hunt, R., Sellers, J. and Franklin, W. "Resource and Environmental Profile Analysis : A Life Cycle Environment for Products and Procedures". Environmental Impact Assessment, Spring. (1992)
Kussuyani, Y., Anwar, C. Aplikasi SNI 7390:2008. Analisis Bioetanol dan Campurannya dengan Bensin. LEMIGAS. Jakarta. (2009)

Samhan, Hasbi. Kontribusi Sektor Transportasi Terhadap Pencemaran Kota Bandung. Skripsi. Program Studi Teknik Lingkungan Institut Teknologi. Bandung. (2012)

Schempf, Noellette Conway. "Case Study: Economic Input-Output Life-Cycle Assessment of Asphalt versus Steel Reinforced Concrete for Pavement Construction". Posner Hall. Carnegie Mellon University, Pittsburgh. (1999)

Stilwell, J., Canty, R., Kopf, P. and Montrone, A. Packaging for the Environment. New York : American Management Association. (1991)

Svoboda, Susan. Note on Life Cycle Analysis. CEMP University of Michigan. (1995) 